\title{
Term Infant with Echogenic Fetal Lung Mass on Prenatal Sonogram
}

\section{Amir H Navaei, Dora Alvarez, Benamanahalli Rajegowda* and Suresh Khanna}

Division of Neonatology and Pulmonary, Department of Pediatrics, Lincoln Hospital Medical and Mental Health center, Bronx, New York, Affiliated with Cornell University, USA

\begin{abstract}
Postnatal management of infant with prenatally diagnosed fetus with Echogenic fetal lung depends on the infant's system at the time of delivery. Infant with large lesions can present with symptomatology at birth whereas a symptomatic infant with normal X-ray requires CT scan or more advance MRI studies between 4-6 weeks prior to discharge from birth facility.
\end{abstract}

Keywords: Echogenic fetal lung; Prenatal diagnosis

\section{Case History}

A full term male infant was delivered via normal spontaneous vaginal delivery (NSVD) to a 35 year-old G6P6006 mother with good prenatal care. Maternal antenatal laboratory results were normal. A maternal prenatal sonogram at 20 weeks gestation showed a solid echogenic mass in the left hemithorax (Figure 1). A second ultrasound confirmed the initial findings, and showed a solid echogenic mass of $2.7 \times 3.9 \mathrm{~cm}$ in size (Figure 2). The mother received a Penicillin prophylaxis for positive Group B streptococcus colonization. The infant's Apgar score was 9/9 at 1/5 minutes respectively.

The infant weighed $3070 \mathrm{~g}$ at birth and physical examination was appropriate for its age, with no abnormality detected. The infant remained clinically stable on room air without developing respiratory distress. The infant's chest rotengogram (CxR) was normal (Figure 3 ). The computerized tomogram (CT) of the infant's chest showed a well demarcated, consolidated mass in the left lower lobe which had a solid and a cystic component, suggesting a diagnosis of a congenital pulmonary adenomatoid malformation (CPAM) or a bronchopulmonary sequestration (BPS) of the lung (Figure 4). A Doppler ultrasound of the left lung showed a solid mass, with no feed vessel thereby suggesting BPS as a likely diagnosis (Figure 5). The baby remained asymptomatic and was discharged home to the parents with scheduled follow up appointments with a pulmonologist and a general pediatrician. The parents were also educated about the infant's clinical condition.

The infant did well post-natally with normal growth and development. The infant underwent a thoracoscopic lobectomy of the left lower lobe (LLL) of the lung at 6 months of age. The final diagnosis was intra-lobar sequestration. The infant has been doing well since surgery and no complications were reported.

\section{Discussion}

Congenital fetal parenchymal lung malformations are uncommon but well documented lung abnormalities. The incidence of such abnormalities is 1 in 10,000 to 35,000 live births, with congenital pulmonary adenomatoid malformation (CPAM) and bronchopulmonary sequestration (BPS) being the most common. These are also the most common lung abnormalities that are diagnosed on prenatal ultrasound [1]. With the improvement in imaging techniques over the past decade, the diagnosis and management of lung abnormalities has completely changed [2].

The exact pathophysiology of congenital lung abnormalities is unclear, but CPAMs are characterized by localized abnormal growth of lower respiratory structures during the pseudo-glandular period of fetal development (7 to 17 weeks) [3]. They are characterized by a cystic or solid intrapulmonary mass, usually unilobar with a slight predilection for the lower lobes that is usually diagnosed on routine antenatal ultrasound performed around 18 to 20 weeks of gestation [1]. They receive their blood supply from the pulmonary circulation. By contrast, BPS could manifest as an intra-lobar or extra-lobar malformation which may derive its blood supply from the ascending aorta. BPS presents as homogenous, echogenic, wedge shaped lesions on antenatal ultrasound [4]. Extra-lobar BPS may be associated with other malformations. Some are hybrid malformations of CPAM and BPS and are usually intra-lobar, receiving their blood supply from both pulmonary and aortic circulations. CPAMs are classified into 5 subtypes based on modified histopathological descriptions by Stocker (Table 1) [5]. An alternative classification of CPAMs was later proposed by Adzick, et al. [6] in which macrocystic CPAMs comprise single or

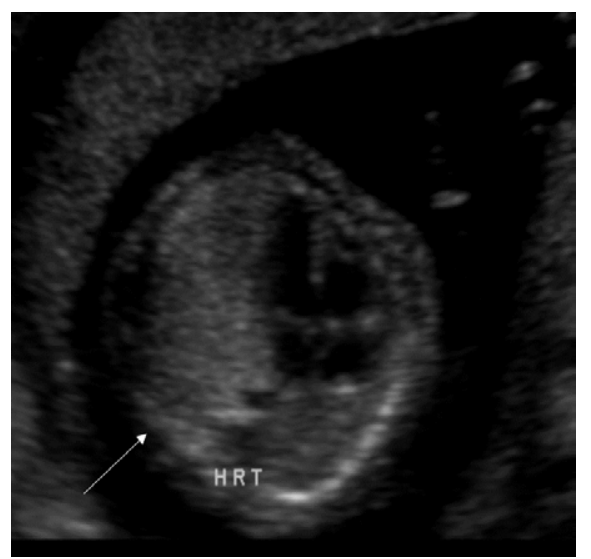

Figure 1: Maternal prenatal sonogram at 20 weeks gestation showing echogenic mass In left hemithorax (indicated by arrow).

*Corresponding author: Benamanahalli K Rajegowda, MD, Lincoln Medical and Mental health Center, Bronx, New York, USA, Tel: 718-579-5360; E-mail: bkraje@hotmail.com

Received April 09, 2015; Accepted April 27, 2015; Published May 04, 2015

Citation: Navaei AH, Alvarez D, Rajegowda B, Khanna S (2015) Term Infant with Echogenic Fetal Lung Mass on Prenatal Sonogram. J Neonatal Biol 4: 176. doi:10.4172/2167-0897.1000176

Copyright: (c) 2015 Navaei $\mathrm{AH}$, et al. This is an open-access article distributed under the terms of the Creative Commons Attribution License, which permits unrestricted use, distribution, and reproduction in any medium, provided the original author and source are credited. 
Citation: Navaei AH, Alvarez D, Rajegowda B, Khanna S (2015) Term Infant with Echogenic Fetal Lung Mass on Prenatal Sonogram. J Neonatal Biol 4: 176. doi:10.4172/2167-0897.1000176

Pge 2 of 3

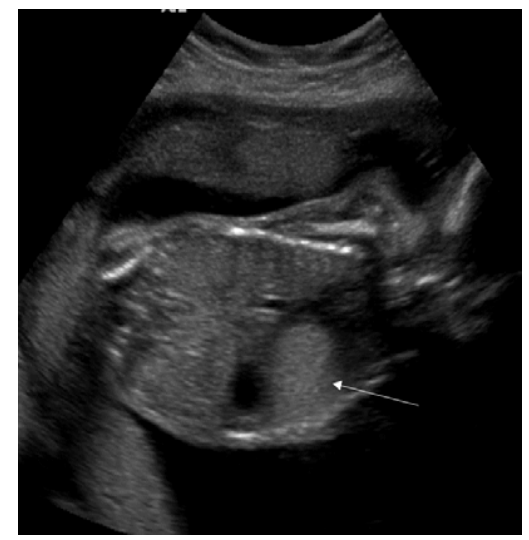

Figure 2: Second ultrasound at 23 weeks 6 days confirmed the initial findings, showing a solid echogenic mass $2.7 \times 2.9 \mathrm{~cm}$ (arrow).

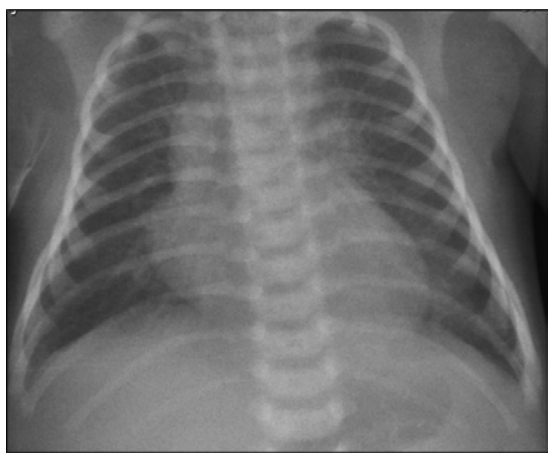

Figure 3: Normal chest X-ray of infant at birth.

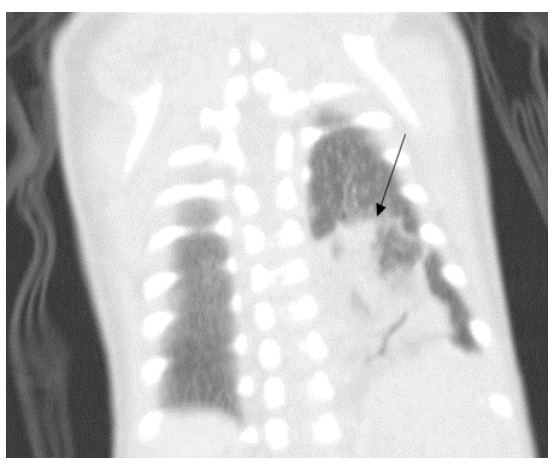

Figure 4: Chest CT of the infant showing well demarcated, consolidated mass in left lower lobe (arrow).

multiple cysts of $\geq 5 \mathrm{~mm}$ in diameter, and microcystic CPAMs are more solid, bulky tumors of $<5 \mathrm{~mm}$ in diameter. Fetal abnormalities associated with CPAM are listed in (Table 2).

\section{Prenatal diagnosis and management}

Detection of CPAMs via the 18 to 20 week antenatal ultrasound is $100 \%$ effective in some studies, but the sensitivity decreases with later ultrasound studies. CPAM growth accelerates at 20 weeks and is maximal around 28 weeks, but decreases thereafter [7]. Earlier diagnosis of CPAMs is possible with $3 \mathrm{D}$ ultrasound, which is also helpful in the diagnosis of other fetal malformations and dysmorphology, while color
Doppler may help in diagnosing hybrid lesions of BPS. MRI, though not commonly used, may diagnose small lesions and cystic CPAMs [7]. Large CPAM lesions require close follow up, as they may be associated with polyhydramnios and hydrops fetalis [1]. Crombleholme proposed using the CVR ratio (head circumference to CPAM volume) to predict the fetal outcome [8]. The most rapid increase in the CVR ratio seems to occur between 20 to 25 weeks. CPAMs with a CVR ratio of $<0.16$ correlates with a $94 \%$ survival rate and a $<3 \%$ risk of developing hydrops fetalis [7]. Fetal intervention is available for certain selected cases with normal karyotype and the absence of associated anomalies. The intervention includes aspiration and drainage of the dominant cyst, amniocentesis and open surgical resection of the lesion [1]. Close surveillance is important as some CPAM lesions may increase in size and some may even regress partially. Prenatal betamethasone treatment for CPAMs with hydrops fetalis has improved survival rates $[7,4]$. Pregnancies complicated by CPAMS should be monitored in tertiary care centers, but once the lesions are detected on ultrasound, the mothers can be managed in regional centers [3].

\section{Postnatal management}

Postnatal management of infants depends upon the infant's symptoms at the time of delivery. Infants with large lesions can present with respiratory distress, tachypnea, and hypoxemia and require ventilator support. Infants with abnormal respiration and chest radiograph require a $\mathrm{CT}$ scan to confirm the presence of a large lesion and require a lobectomy upon confirmation [1].

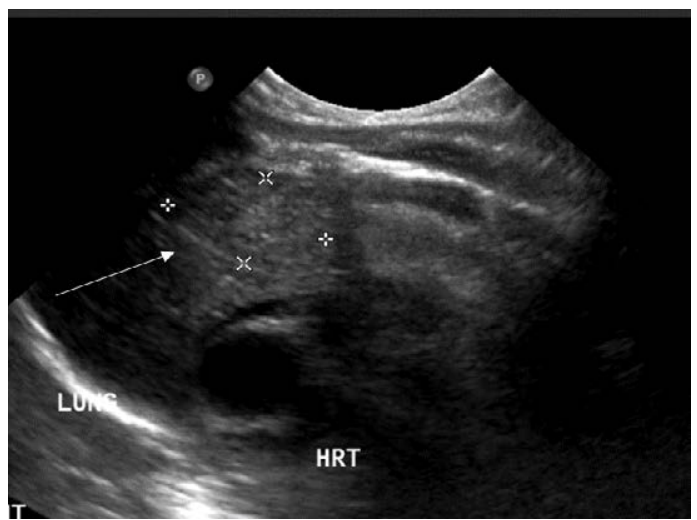

Figure 5: Postnatal Doppler ultrasound of the left lung showing a solid mass, demarcated by arrow and markers. (P-, HRT- heart, T-).

\begin{tabular}{|c|l|}
\hline $\begin{array}{c}\text { Subtype of } \\
\text { CCAM }\end{array}$ & Histological Classification \\
\hline 0 & Involves all lobes, not compatible with life \\
\hline 1 & Single or multiple cysts $>2 \mathrm{~cm}$ in diameter (most common type) \\
\hline 2 & Single or multiple cysts $<2 \mathrm{~cm}$ in diameter \\
\hline 3 & Solid mass $<0.5 \mathrm{~cm}$ in diameter \\
\hline 4 & Large, peripheral thin wallet cysts - usually asymptomatic \\
\hline & Table 1: Modified histological classification of CPAMs. \\
\hline
\end{tabular}

\begin{tabular}{|c|c|}
\hline $\begin{array}{c}\text { Location of Associated } \\
\text { Abnormality }\end{array}$ & $\begin{array}{c}\text { Associated Abnormality } \\
\text { Lung }\end{array}$ \\
\hline Non-lung: Renal & $\begin{array}{c}\text { Renchopulmonary sequestration, lobar } \\
\text { emphysema }\end{array}$ \\
\hline Non-lung: Gastrointestinal & Intestinal atresia, esophageal duplication cyst \\
\hline Non-lung: Cardiac & Congenital Heart Disease \\
\hline
\end{tabular}

Table 2: Fetal Abnormalities Associated with CPAM. 
Citation: Navaei AH, Alvarez D, Rajegowda B, Khanna S (2015) Term Infant with Echogenic Fetal Lung Mass on Prenatal Sonogram. J Neonatal Biol 4: 176. doi:10.4172/2167-0897.1000176

Pge 3 of 3

Asymptomatic infants with a normal chest radiograph require a CT scan between weeks 4 and 6 or a prior to discharge from birthing facility. Some studies recommend low dose computed tomography or angiography, but experience with these diagnostics is very limited for neonates or young infants. Doppler ultrasound and MRI may be needed to differentiate between CPAMs and BPS. These infants are not only at risk for frequent lung infections, pneumothorax, and lung abscesses, but also have a slightly increased risk for malignancy. Though there are some controversies regarding the management of these asymptomatic children, most authors recommend surgical resection during the first year to prevent infection and malignant transformation, as well as to allow compensatory growth $[1,9,3,7]$. Air travel should be avoided prior to surgical resection due to the risks of pneumothorax [10].

\section{Lessons for Clinicians}

Most of the infants are still born at community based hospital, it's important for Family Practioners and Pediatricians to be familiar with the following:

- To learn the pathophysiology and natural history of congenital lung diseases.

- To consider a postnatal CT scan (prior to discharge or in 4-6wks after discharge) even in infants with normal chest radiograph.

- To be aware of the high risk of lung infections, pneumothorax, lung abscess as well as increased risk for malignancy in initially asymptomatic infants.

- To be aware of a high incidence of pneumothorax during air travel.

\section{References}

1. Lakhoo K (2009) Management of congenital cystic adenomatous malformations of the lung. Arch Dis Child Fetal Neonatal Ed 94: F73-76.

2. Tsai HF, Cheng YC, Ko HC, Kang L, Tsai PY, et al. (2013) Prenatal diagnosis of fetal congenital cystic adenomatoid malformation of the lung using three dimensional ultrasound? Comparison between the 20th and 21st centuries. Taiwan J Obstet Gynecol. 52:90-96.

3. Khalek N, Johnson MP (2013) Management of prenatally diagnosed lung lesions. Semin Pediatr Surg 22: 24-29.

4. Mann S, Wilson RD, Bebbington MW, Adzick NS, Johnson MP (2007) Antenata diagnosis and management of congenital cystic adenomatoid malformation. Semin Fetal Neonatal Med 12: 477-481

5. Stocker JT, Madewell JE, Drake RM (1977) Congenital cystic adenomatoid malformation of the lung. Classification and morphologic spectrum. Hum Pathol 8: 155-171.

6. Adzick NS, Harrison MR, Glick PL, Golbus MS, Anderson RL, et al. (1985) Fetal cystic adenomatoid malformation: prenatal diagnosis and natural history. J Pediatr Surg 20: 483-488.

7. Kotecha S, Barbato A, Bush A, Claus F, Davenport M, et al. (2012) Antenatal and postnatal management of congenital cystic adenomatoid malformation. Paediatr Respir Rev 13: 162-170.

8. Crombleholme TM, Coleman B, Hedrick H, Liechty K, Howell L, et al. (2002) Cystic adenomatoid malformation volume ratio predicts outcome in prenatally diagnosed cystic adenomatoid malformation of the lung. J Pediatr Surg 37: 331-338.

9. Witlox RS, Lopriore E, Oepkes D, Walther FJ (2011) Neonatal outcome after prenatal interventions for congenital lung lesions. Early Hum Dev 87: 611-618.

10. Madan K, Vishwanath G, Singh N (2012) In-flight spontaneous pneumothorax: congenital cystic adenomatoid malformation of the lung. Respiration 83: 554558. 